\title{
3 Research Square

\section{Effectiveness of jogging, eye movement exercises, and diaphragmatic breathing in patients with migraine: a randomized controlled trial}

Mohammad Dawood Rahimi ( $\sim$ dawoodrahimi@msn.com )

Ferdowsi University of Mashhad https://orcid.org/0000-0002-6282-1862

Fatemeh Alidoosti

Khayyam University

Pouriya Hassani

University of Padova School of Psychology: Universita degli Studi di Padova Scuola di Psicologia

Mohammad Mahdi Ghasemi

Mashhad University of Medical Sciences

Javad Salehi Fadardi

Ferdowsi University of Mashhad

\section{Research Article}

Keywords: Migraine treatment, jogging, eye movement exercises, diaphragmatic breathing

Posted Date: June 15th, 2021

DOI: https://doi.org/10.21203/rs.3.rs-309380/v2

License: (9) This work is licensed under a Creative Commons Attribution 4.0 International License.

Read Full License 


\section{Abstract}

Background: The recurrent and progressive presence of maladaptive stress response-related activities or electrophysiological dysresponsiveness are apparent in a brain with migraine.

Objectives: Various methods have been suggested to regulate stress response-related activities in a brain with migraine, including jogging, eye movement exercises, and diaphragmatic breathing.

Methods: A three-group, double-blind, and randomized design with pre-test, post-test, and follow-up assessments was used to test the effectiveness of jogging, eye movement exercises, and diaphragmatic breathing in the treatment of patients with migraine. International Classification of Headache Disorders 3rd edition (ICHD-3) was used to diagnose the patients with migraine, who were randomly assigned to one of the three study groups to perform either 12 consecutive weeks of (a) jogging plus eye movement exercises $(n=22) ;(b)$ jogging plus diaphragmatic breathing $(n=19)$; or (c) treatment as usual (TAU), receiving prescribed medication $(n=22)$ group.

Results: The results of a series of MANCOVA showed that patients in the two experimental groups showed significant $(p<.05)$ reductions in the frequency, duration, and intensity of their migraine attacks compared to the TAU group. Moreover, the frequency of menstrual cycle-dependent headache attacks and over the counter drugs use were reduced, and the quality of sleep and drinking water were improved at post-test and a 12-month follow-up.

Conclusion: The results suggest that jogging plus eye movement exercises or jogging plus diaphragmatic breathing can be used as effective alternative interventions in the treatment of migraine.

\section{Introduction}

Alterations in response to daily life stressors and neuronal excitability hint the brain with migraine. ${ }^{1,2}$ Examples of such stressors could be observed as maladaptive stress responses in both peripheral and central nervous systems. ${ }^{3,4}$ The migraine pain also depends on the activation and sensitization of firstorder or cranial neurons and sensitization and altered habituation of second-order or cortical neurons. The activation or sensitization is determined by the quantity, duration, or presence of other elements in the brain (e.g., pituitary adenylate cyclase-activating peptide and calcitonin gene-related peptide) that can lead to (a) genetic modulation; (b) modulating cells communications (e.g., transcription factors); and (c) cerebral blood flow (CBF) or vascular tone alteration (i.e., vasodilation).$^{4}$ For instance, eye-brain electrochemical transduction and retinal nerve fiber alterations, structural and functional abnormalities in the endothelial progenitor cells, interlinks between mitochondrial energy production, reactive oxygen species (ROS) availability (e.g., Nitric Oxide-NO), and ion homeostasis (e.g., calcium influx) seem to play key initiating roles in a brain with migraine. ${ }^{4-8}$ Therefore, regulation and availability of signaling biomolecules (e.g., NO and brain-derived neurotropic factor-BDNF) and regulation of signaling pathway 
(e.g., cAMP-response element binding protein-CREB) are essential during health and illness, including migraine attacks, as stressful insults to the brain. ${ }^{9,10}$

Although non-steroids anti-inflammatory drugs (NSAIDS), antidepressants, triptans, gepants, and anti-epileptic drugs are the frequently used medications for migraine attacks, most of these medications have low therapeutic gain, low resolution of symptoms, and undesirable side effects. ${ }^{11,}{ }^{12}$ For example, in the presence of triptans or morphine, NO boosts the activation of trigeminal pathways or increases the risk of medication overuse headache $(\mathrm{MOH}) .{ }^{13,14}$ Nevertheless, the chronic administration or high doses of antidepressants suppress the expression of the signalling biomolecule genes. ${ }^{15}$ Moreover, the manipulation of BDNF gene expression may contribute to the development of other disorders or diseases including anxiety, depression, or chronification of migraine. ${ }^{16}$ Considering the complications, developing novel, safe, multidimensional, and non-pharmacological interventions appears to offer a promising method for decreasing the load of the stress insults in a brain with migraine. ${ }^{17}$

The effects of regular aerobic exercises or progressive relaxation techniques on pain have been documented in previous studies. ${ }^{18-20}$ Therefore, the present study takes the assumption that regular aerobic exercises in adjunct to visual exercises, exercise-induced, nasal, or diaphragmatic breathing maintain the brain homeostasis, improve the brain function, protect the brain against various-induced toxicities, and relieve pain experience. Inhibition of excessive presence of N-Methyl-D-Aspartate (NMDA) receptors or regulation of serotonin or glutamate excitatory signaling, and promotion of BDNF gene expression are the expected positive outcomes in the present study. ${ }^{21-31}$ That is, through regulation of local and cortical endothelium releasing factors (e.g., NO and BDNF), regular aerobic exercises, nasal breathing, and visual exercises facilitate and re-arrange cortical and oscillatory feedback signaling between cranial motor nerves, brain stem, thalamus, hypothalamus, motor, and sensory cortices, all of which are closely related to a brain with migraine. ${ }^{32-37}$

\section{Methods}

\section{Study population}

First, a power analysis was conducted the sample size needed for the present effectiveness study. Considering the similar studies in the field and the novelty of both experimental interventions, a priori effect size of .175 (midpoint between small and medium effect size for MANOVA models) deemed suitable for the present study. In the G*Power software, Power was entered as .80 (Cohen, 1992), alpha a $=.05$, number of groups $k=3$, and response variables $=3$ (i.e., pain frequency, duration, and intensity), which yielded a total sample size of $n=45$. Because in a study with a 12-month follow up attrition rate could be as high as $.40 \%$ then 63 participants deemed necessary to be included at the baseline assessment. All participants in the final sample were right-handed ${ }^{38}$ Persian-speaking female patients ${ }^{39}$, 40 (mean age $=31.19 ; S D=5.67$; range of $19-40$ ) with migraine (33.3\% with aura (MwA); $66.7 \%$ without aura (MwoA)). Participants were invited to participate in a scientific study that might help migraine 
treatment. The study population consisted of 764 patients with migraine who were admitted to several local state hospitals between September 2015 and August 2016. After eligibility assessment (the study flowchart below), 353 individuals did not meet the study criteria (below) and 276 were unable to participate in the study. Of remaining 135 patients, another 72 participants were randomly deleted to get to the final sample $n=63$ for the baseline assessment. Only 10 participants were missed during the follow-up, hence the final data analyses were conducted with all remaining participants in the study. Participation in the study was voluntary. During their enrolment, participants filled out a questionnaire on demographic information, history of migraine, socioeconomic status, and migraine type (Table 1).

Inclusion criteria were (a) 18-50 years of age ${ }^{41}$ (b) a confirmed diagnosis of migraine based on the International Classification of Headache Disorders (ICHD) criteria; ${ }^{42}$ and (c) a history of migraine (range of attacks $=1-14$ days for four weeks) over the last 12 months regardless of the migraine type (i.e., with aura (MwA) or without aura (MwoA)). Exclusion criteria were (a) a history of any other neurological, gut, or respiratory-related diseases including concomitant diagnosis of other headache disorders especially medication overuse headache $(\mathrm{MOH}){ }^{43}(\mathrm{~b})$ any kind of surgery that restricts their ability to jog, perform eye movement exercises, and / or breath; or (c) cardiovascular-related diseases, e.g., blood pressure abnormalities. The use of pain medication was allowed between post-test and the follow-up assessments for the patients in the control group. Patients in the experimental groups agreed not to take pain medications, including prophylactics or any other interventions for at least three months in advance of and during the present study. However, if they were experiencing severe pain, they could use limited medication prescribed by their physician. The study flowchart shows flow of the present study from 2016 to 2019. Flowchart.

\section{Ethics approval and consent to participate}

The present study was performed in accordance with the Declaration of Helsinki and was approved by the ethics committee of Mashhad University of Medical Sciences (clinical trial registration number: Ir.mums.fm.rec.1396.362, 22/06/2017). A written informed consent was obtained from the participants. All the methods were performed in accordance with the Guidelines of the International Headache Society for controlled trials of preventive and prophylactic treatments of migraine in adults. ${ }^{44,45}$

\section{Experimental design}

The present study ( $3 \times 3$ factorial design; three groups and three dependent variables) is a randomized, three-armed, and double-blind controlled trial. Although it was an ethical necessity for the participants to know about the nature of the study, neither the participants nor the research assistants responsible for interventions and data collection were not aware of their group allocation. The study aimed to investigate whether jogging plus eye movement exercises or jogging plus diaphragmatic breathing could be effective in alleviating migraine symptoms compared to a control group that used prescribed medications for migraine (i.e., treatment as usual). 
All participants had to meet the inclusion criteria and be flexible about the terms of the study after their diagnosis was confirmed by two consultant neurologists at a local state hospital based on ICHD criteria

42. The entire sample was tested over a 46-week period between August 2016 and July 2017. By using a paper-based, baseline headache diary, the sample was screened for frequency, duration, and intensity of attacks in the last three months. ${ }^{46,47}$ Next, using the random digit table, participants were randomly (1:1:1) assigned to one of the experimental groups, i.e., eye movement exercises $(n=22)$ or diaphragmatic breathing $(n=19)$ or to the control group $(n=22)$. All the data were recorded by three research assistants who were blind to the study design. The data analysis was also conducted by one of the co-authors, who was blind to the study design and its hypotheses.

\section{Randomization procedure}

Because the present study was based on a double-blind design, clinicians, experimenters, and research assistants who were working with the patients were not aware of the nature of the study design and procedures. Participants were informed only about what they were expected to do but not about their group allocation and other participants in the study, and the study design and goals. To reduce the risk of prediction for a sample size of $n>50$, we used telephone (secure) allocation of participants by an independent person in line with instructions for simple random method ${ }^{48}$. Before proceeding to the next stage, the inclusion and exclusion criteria of the present study were monitored and checked. For example, if a participant was on a prescribed or non-prescribed medication, they were recommended to stop their medication in a tapering manner (i.e., over a 6-week period). Moreover, patients were asked and screened for any types of smoking, however, no participant were deemed to have smoking habit.

One experimenter was randomly assigned to each group to execute the participants' enrollment and interventions' assignments in each group during study. By using a paper-based diary, experimenters were instructed and scheduled to monitor and record medications, menstrual cycles, sleeping, drinking water, and exercise intolerance behaviors in the experimental and control groups. The participants were told that their participation was voluntary, and they could withdraw from the experiment at their will. They were told that they are part of a study on the migraine.

\section{Interventions}

\section{Jogging plus eye movement exercises or jogging plus diaphragmatic breathing instruction}

There were two experimental groups. The first experimental group performed jogging plus eye movement exercises. The second experimental group performed jogging plus diaphragmatic breathing instruction.

Jogging required circling around the outer ring of a local public park for $3.2 \mathrm{~km}(\approx 25$-min). During the jogging, they were instructed to follow a breathing rhythm that required two relaxed, deep nasal 
inhalations, a repose, and two deep oral exhalations. The jogging was exercised every other day (between 5:00 p.m. and 7:00 p.m.) over a period of 12 weeks.

The eye movement exercises included horizontal (dextroversion / levoversion) and vertical (sursumduction / deorsumduction) conjugated eye movements ${ }^{49}$. Participants performed a 5-min eye movement exercise 30-min before having their breakfast every morning and 30-min before going to bed at night for 12 weeks. The 5 -min bedtime phase was initiated by 15 -round movements of the right-hand index finger, followed by 15 -round left-hand index finger movements in the horizontal visual field, which was followed by the same procedure in the vertical visual field with a front-forward, fixed head with the eyes following the finger in a constantly controlled manner (Figure 1). The 5-min morning phase was initiated, sustained, and terminated with the same procedure, but instead of moving the index finger in the visual field, the head was moved horizontally ( 30 rounds laterally) and then vertically ( 30 rounds up and down) with fixed eyes on a fixed index finger in the visual field (Figure 2). ${ }^{50,51}$ Figures 1 and 2 show participants' hands and head-guided eye movement exercises in the experimental groups.

The diaphragmatic breathing practice required a deep nasal inhalation, a two-second repose, and a long, deep oral exhalation three times a day around 7:00 a.m., 2:00 p.m., and 9:00 p.m. for 5-min for 12 consecutive weeks. Participants were persuaded to focus on their breathing while inhaling and exhaling. ${ }^{52,53}$

During the eye movement exercises and diaphragmatic breathing practice, participants were asked to sit in an upright position and plant their feet on the ground at a 90-degree angle to match the extension of their shoulders. Moreover, they were instructed to fix their head horizontally, leveled with their body. They were also asked to arch their back completely and slouch forward. The position was followed by rolling shoulders back and dropping them down. The preparation phase was ended by a deep breath and relaxation (Figure 3$) .54$

\section{Tutorial sessions}

After the randomization and group allocation, two research assistants who were blind to the objectives and nature of the study were instructed to teach the participants how to perform eye movement exercises and diaphragmatic breathing, in two face-to-face sessions (each session $=30-\mathrm{min}$ ). Although jogging was taught in a separate and a face-to-face session (30-min) by another a research assistant, for everyone, for each study group, jogging was accompanied, performed, and monitored every session for each experimental group by two specific research assistants.

\section{Control group}

The control group was receiving medical treatment as usual, which solely consisted of common prescribed medication to help with the migraine symptoms. Because there were a variety of prescribed prophylactic medications (e.g., Propranolol, Imipramine) and their effects on the migraine symptoms were not a goal for the present study, it was not necessary to keep a record of the type of medication that 
participants were using over the course of the study. Therefore, like the experimental groups, they were monitored regularly to reduce the attrition rate, and completed all the study measures at the baseline, post-test, and the follow-up assessments.

\section{Procedure}

To measure the duration, frequency, and intensity of pain, the study measures were administered at the baseline, post-test, and a 12-month follow-up-by using a baseline headache diary over three months. Moreover, weekly telephone follow-ups were made to enquire about the participants' experiences of pain, use of prescribed or non-prescribed medication, menstrual cycle, sleeping pattern, drinking water, or other related behaviors for both experimental and control groups. The telephone calls also helped minimize the participants' dropouts. Participants were also reassured that they could have control visits during the study in case of experiencing migraine attacks or complications that could affect the intake of regular prescribed or non-prescribed medication. However, none of the participants in the experimental groups reported referring to their physician or resuming the use of migraine prescribed or non-prescribed medication at any of phone calls or follow-up assessments in the experimental groups. Therefore, there was no data on prescribed or non-prescribed medication relapse for the experimental groups. The same experimenters administered all study measures at the baseline, post-test, and the follow-up assessments.

\section{Measures}

\section{Headache diary}

A paper-based and baseline headache diary was used 46,47 to record the frequency, (i.e., one attack per four weeks, one attack in two weeks, two or three attacks per week, or more than three attacks per week), duration (i.e., 4, 4-24, or 24-72 hours per attack), and the intensity of pain (i.e., moderate (1-3), severe (4-7), and worse possible case (8-10)) per migraine attack during the past four weeks-over three months. The measure has desirable reliability and validity indices 46,47 .

\section{Compliance with intervention}

Based on recorded data and the present study protocols, which included 36 sessions of jogging and 72 sessions of eye movement exercises or 72 sessions of diaphragmatic breathing for each study group, compliance with the intervention was calculated as follows: $36 / 36 \times 100=\%$ compliance or $72 / 72 \times 100$ $=\%$ compliance for each study group ${ }^{55}$. During 36 sessions of jogging and 72 sessions of eye movement exercises or diaphragmatic breathing, each group of participants could skip sessions for a maximum of three (with a minimum compliance of $91.6 \%$ ) or six (with a minimum compliance of $95.8 \%$ ) sessions. Because there were no reports beyond the minimum compliance with procedures, further reports of the factor deemed unnecessary in the data analyses. 


\section{Menstrual cycle, OTC, sleep, changes of drinking water, and exercise intolerance behaviors}

Prior to the study, an experimenter recorded information from the participants on (a) menstrual cycle; (b) over the counter (OTC) drug use; (c) sleep regimens (sleep and wake-up patterns), sleeping hours, wakeup mode ${ }^{56}$; (d) drinking water; and (e) exercise intolerance. Menstrual cycle involved presence or absence of any effects on headache characteristics prior to, during, or after a menstrual period. Sleeping pattern involved going to sleep on time (between 9:00 p.m. and 11:00 p.m.) or late at night (after 11:30 p.m.). Sleeping hours included sleeping less than or more than seven hours per night (between 10:00 p.m. and 7:00 a.m.) ${ }^{57,58}$. In addition, drinking water was also recorded for the participants ${ }^{59}$. However, any incidents of muscle cramps, fatigue, chronic dizziness, and vomiting, which were related to exercise intolerance were recorded. The data was recorded every other day during the experiment and every week during the 12-month follow-up for experimental and control groups. The rationale for recording and analyzing this data was to test whether the interventions influenced such variables beside migraine pain characteristics.

\section{Data analysis}

To test the relative effect of jogging plus eye movement exercises or jogging plus diaphragmatic breathing, three multivariate analyses of covariance (MANCOVA) were conducted. To ensure that there were no missing data, initial data evaluation was performed for experimental and control groups. Next, assumptions of homogeneity, linearity, and normality of variance-covariance matrices were calculated and a $p$-value $\geq .05$ was set for all analyses. The results of models' fitness tests did not reveal any violation of underlying assumptions. In each model, group (three levels) was entered into the model as factor, pain characteristics (i.e., frequency, duration, and intensity of pain) at baseline were entered as covariates, and pain characteristics at the post-test and follow-up were entered into the model as dependent variables. Moreover, as secondary analyses, Cochran's tests were calculated to measure the effects of the two types of interventions on menstrual cycle, OTC, sleep, and drinking water as behavioral outcomes from baseline to post-test and the 12-month follow-up.

\section{Results}

Table 2 shows means and SDs of frequency, duration, and intensity of pain in each study group at baseline, post-test, and the 12-month follow-up assessments.

\section{Primary data analyses}

In each MANCOVA model, group showed a significant multivariate effect on the frequency (Wilk's $=.20$;

$F_{(4,96)}=28.93 ; p=.001 ; \eta 2$ (Cohen's $\left.d\right)=.54(2.16)$ ), duration (Wilk's $=.16 ; F_{(4,96)}=34.34 ; p=.001 ; \eta 2$ $($ Cohen's $d)=.58(2.35)$ ), and intensity (Wilk's $=.09 ; F_{(4,96)}=53.14 ; p=.001 ; \eta 2$ (Cohen's $\left.d\right)=.68$ (2.91)) of the pain at the post-test and follow-up assessments. Pairwise comparisons showed that, 
compared to the control group, the experimental groups showed significant improvements in all pain characteristics at the post-test and follow-up assessments (Table 3). There was no significant difference between the two experimental groups on any of the pain characteristics. The effect sizes for all models were greater than Cohen's $d=.80$ for a large effect size (Table 3 ). Figure 4 shows changes in the migraine pain across assessment points for each group. Figure 4. Migraine pain (frequency; ranges 1-9 attacks, duration; ranges 1-8 hours/attack, and intensity; ranges a scale of 1-7/attack during the last four-week) changes in each study (EM = eye movement exercises, $\mathrm{DB}=$ diaphragmatic breathing, control) group across three assessment points (pre-test, pot-test, and follow-up).

The results of a series of Cochran's tests were used to test changes in the patients' menstrual cycle, OTC, sleep pattern, and drinking water across the assessment points and showed significant improvements for the experimental groups but not for the control group (Table 4). None of the participants in the experimental groups complained of adverse effects like muscle cramps, fatigue, chronic dizziness, or vomiting on exertion or after exercise.

Given the loss of participants from post-test to the follow-up (see Flowchart), we did not have full compliance with the present study intervention protocols; the compliance rates were: 53/63 $\times 100=$ $84.1 \%$ compliance for the total sample; $20 / 22 \times 100=90.9 \%$ compliance for the jogging plus eye movement exercises group; $18 / 19 \times 100=94.7 \%$ compliance for the jogging plus diaphragmatic breathing; and $15 / 22 \times 100=61.1 \%$ compliance for the control group .

\section{Discussion}

The present study tested the effectiveness of jogging, eye movement exercises, and diaphragmatic breathing in patients with migraine. The first experimental group received jogging plus eye movement exercises and the second experimental group received jogging plus diaphragmatic breathing, whereas the control group only received treatment as usual. The results showed significant effects of the interventions on the patients' symptoms in the experimental groups (Figure 4 and Table 3 ). Therefore, regular aerobic exercises (i.e., jogging) and practicing body-mind awareness (i.e., eye movement exercises and diaphragmatic breathing) appear to elucidate the negative effects of stressful insults in the brain, on the body muscles, respiratory rate and depth, and the flow of biomolecules and hormones (i.e., Nitric Oxide (NO), brain-derived neurotrophic factor (BDNF), and adenosine monophosphate-activated protein kinase (AMPK)). These effects could stem from various possible mechanisms, including (a) brain-gut and neuroimmune axis (e.g., hypothalamus-pituitary-adrenal (HPA); (b) brain-brain reciprocal interlinks (e.g., hippocampus-anterior cingulate cortex and medial-prefrontal cortex (MPFC) oscillations); and (c) circadian disruption and biomolecular dysregulation (e.g., oxidative stress and neurogenic inflammation), each of which may play a key initiating role in spurring migraine-related symptoms ${ }^{60-63}$.

Although the results of a meta-analysis ${ }^{20}$ suggested that the effect of aerobic exercise on patients with migraine is only related to the frequency of the attacks, in a recent study ${ }^{64}$, aerobic exercises are assumed to influence all aspects of migraine pain including frequency, duration, and intensity. The 
paradoxical findings in the literature on the effectiveness of aerobic exercise could be related to the following reasons. First, based on the International Headache Society (IHS) recommendations ${ }^{45}$, 47 , one major drawback of previous studies is heterogeneity in applying headache-related outcome measures. Second, some studies have failed to adequately address issues related to blinding, sample size, designing, and randomization. Third, no study has compared the outcomes of aerobic exercises on patients with migraine without aura (MwoA) and patients with migraine with aura (MwA). Forth, evidence was scarce for comparing the outcomes of aerobic exercises and pharmacological treatment of migraine pain. Fifth, in no study so far aerobic exercise has been complemented with another non-medication intervention; therefore, this was the first study that, based on findings from the brain with migraine studies, combined jogging with eye movement exercises or diaphragmatic breathing to decrease kinesiophobia or sensitivity to movements in patients with migraine ${ }^{65,66}$.

As a diagnostic criterion, patients with migraine have a fear of movement or kinesiophobia ${ }^{67-69}$. To develop readiness for and potentiate neural responsiveness to a full-body exercise and to improve body awareness 52,53 , the present study provided the patients with eye movement exercises or diaphragmatic breathing ${ }^{70-72}$. Considering the neural or Hebbian learning, stimulating brain on a regular basis adjusts brain functions at the molecular level (e.g., signaling mechanisms and memory formation) ${ }^{73}$. Eye movement exercises are identified to activate widespread, interconnected cortical and subcortical networks such as superior colliculus, oculomotor network (ON) in the brain stem, dorsolateral prefrontal brain cortex, basal ganglia, subthalamic structures, substantia nigra pars reticulata, visuo-motor, parietal, and posterior cingulate cortices ${ }^{74-78}$. Each of these networks plays an excitatory or inhibitory role in pain processing 79,80 . Therefore, performing eye movement exercises on a regular basis stimulates or potentiates almost all major parts of the brain that are important in the experience of the pain. The corneoretinal potential (CRP) transduction by eye movement exercises is a bioelectrical signal, which is produced by two modes of polarities during eye movement exercises: a positively charged end (cornea) and a negatively charged end (retina) ${ }^{81}$. The conjugated eye movement exercises (i.e., from right to left or from top to bottom and the vice versa) transduces sequential negative or positive electrical charges on the retina ${ }^{82}$. These types of training-induced transduction should potentiate synaptic plasticity and facilitate myelination mechanisms by (a) regulating signal transmission (i.e., neuromodulation of ion channels and neurotransmitters); (b) synchronizing oscillations (i.e., frequency, amplitude, or phase); and (c) cortical reorganization or enhancement of timing within related cortical-cortical or cortical-subcortical brain networks (i.e., enhancement of memory, visuospatial accuracy, decision-making, or task switching) ${ }^{83-87}$.

In the present study, another essential guided behavior was diaphragmatic breathing. It should be noted that jogging itself may increase exercise-induced stress insults in brain with migraine; however, diaphragmatic breathing helps with promoting stress-response control indices and potentiating cortical readiness prior to jogging 88,89 . Diaphragmatic breathing can improve brain function via the following mechanisms: (a) chemical, which involves the regulation of biomolecules such as adenosine, melatonin, orexin, or calcitonin-gene-related peptide (CGRP); (b) mechanical, which involves enhancing the rate, 
length, or intensity of breathing at the cortical level; and (c) cortical-subcortical control, which is related to shared breathing centers and headache-related networks such as brainstem and medullary centers ${ }^{90-93}$. Together, jogging, eye movement exercises, and diaphragmatic breathing may induce mitochondrial oxidative phosphorylation, electrical transduction, ionic, and biomolecule homeostasis that can explain primary and secondary outcomes of the present study.

All participants in the present study were female patients with migraine. This may limit the generalizability of our findings to male patients with migraine. Subsequently, the same study should be also conducted with male migraine patients. Moreover, heterogeneity in the rate of prescribed and OTC medication use in the control group was another limitation of the present study. Moreover, we did not ask patients in the control group to keep a journal of any medication that they were taking for their pain because, there is no single or specific medication with consistent or long-term effect for migraine, hence even recording the rate of medication use over a two-year by the patients in the control group deemed an unviable goal and could not help with interpreting the study outcomes. Furthermore, given that the present study was conducted in a Middle Eastern country with a different environment and culture, future studies can replicate the study with patients from different cultural, racial, and ethnical backgrounds. Future studies can also examine the outcomes of the present interventions for other types of headaches, migraine-related comorbidities (e.g., epilepsy, tinnitus, chronic dizziness, or vertigo (e.g., phobic postural vertigo), sleep apnea, or restless leg syndrome), and even for psychopathologies like depression and anxiety.

\section{Conclusion}

The primary outcomes of the present study can be summarized as positive effects of jogging plus eye movement exercises or jogging plus diaphragmatic breathing on decreasing the frequency, duration, and intensity of pain in patients with migraine. The secondary outcomes could be summarized as decreased headache attacks associated with menstrual cycle and use of OTC medication, and on improving sleep and drinking water. Together, interventions used the present study offer promising prophylactic and therapeutic outcomes for patients with migraine.

\section{Clinical implications}

Performing 12 -week jogging (every other day $\approx 25$-min) either with eye movement exercises (60 rounds early in the morning / 60 rounds before the bedtime) or diaphragmatic breathing ( 3 times a day, each time for $\approx 5$-min):

- can significantly reduce the measured aspects of migraine pain characteristics.

- offers a safe and convenient intervention.

- produces no short-term or long-term undesirable side effects.

\section{Abbreviations}


BDNF: Brain-Derived Neurotrophic Factor

cAMP: Cyclic adenosine monophosphate

CBF: Cerebral blood flow

CREB: cAMP-response element binding protein

CRP: Corneoretinal potential

DB: Diaphragmatic breathing

EME: Eye movement exercise

ED: electrophysiological dysresponsiveness

ICHD-3: International Classification of Headache Disorders 3rd edition

$\mathrm{MOH}$ : Medication overuse headache

MwA: Migraine with aura

MwoA: Migraine without aura

NMDA: N-Methyl-D-Aspartate

NO: Nitric Oxide

OTC: Over the counter drugs

PHA: Hypothalamus-pituitary-adrenal

TAU: Treatment as usual

\section{Declarations}

\section{Availability of data and material}

All data generated or analyzed during the present study are included in this manuscript and the datasets used and/or analyzed in the present study are available from the corresponding author on reasonable request.

\section{Ethics declarations}

\section{Ethics approval}


The study was approved by the ethics committee of Mashhad University of Medical Sciences.

Registered trial: Ir.mums.fm.rec.1396.362.

\section{Consent for publication}

All subjects provided written informed consent for publication prior to the present study enrolment.

\section{Competing interests}

The authors declare that they have no competing interests.

\section{Acknowledgement}

We thank our colleagues who commented on an earlier version of the present article, the anonymous reviewers whose comments assisted with the quality of the article, and patients who participated in our study. The authors have no conflict of interest to declare.

\section{Funding}

It should be acknowledged that the present study did not receive any full or partial financial support.

\section{Authors' contributions}

Mohammad Dawood Rahimi: Conceptualization, Methodology, Data curation, Investigation, Project administration, Writing-original draft. Fatemeh Alidoosti: Formal analysis. Pouriya Hassani: Investigation. Mohammad Mahdi Ghasemi: Resources, Supervision. Javad Salehi Fadardi: Supervision, Conceptualization, Methodology, Reviewing \& Editing.

\section{References}

1. Gazerani P. A Bidirectional View of Migraine and Diet Relationship. Neuropsychiatric Disease and Treatment. 2021;17:435.

2. Vives-Mestres M, Casanova A, Buse DC, et al. Patterns of Perceived Stress Throughout the Migraine Cycle: A Longitudinal Cohort Study Using Daily Prospective Diary Data. Headache: The Journal of Head and Face Pain. 2021;61(1):90-102.

3. Dodick DW. A phase-by-phase review of migraine pathophysiology. Headache: the journal of head and face pain. 2018;58:4-16. 
4. $\quad$ Ashina M. Migraine. New England Journal of Medicine. 2020;383(19):1866-1876.

doi:10.1056/NEJMra1915327

5. DeBuc DC, Somfai GM, Szatmáry G, et al. Seeing the Brain Through the Eye: What Is Next for Neuroimaging and Neurology Applications. OCT and Imaging in Central Nervous System Diseases. Springer; 2020:55-82.

6. Polak K, Luksch A, Frank B, Jandrasits K, Polska E, Schmetterer L. Regulation of human retinal blood flow by endothelin-1. Experimental eye research. 2003;76(5):633-640.

7. Zhang C, Hein TW, Wang W, Chang C-I, Kuo L. Constitutive expression of arginase in microvascular endothelial cells counteracts nitric oxide-mediated vasodilatory function. The FASEB Journal. 2001;15(7):1264-1266.

8. Lee S-T, Chu K, Jung K-H, et al. Decreased number and function of endothelial progenitor cells in patients with migraine. Neurology. 2008;70(17):1510-1517.

9. Khosravi A, Nakhaee A, Ghoreishi A, Arefpoor Z, Sadeghi M. Impaired oxidative-antioxidative balance during migraine attack. Biomedical Research and Therapy. 2019;6(2):2996-3002.

10. González-Rodríguez P, Ugidos IF, Pérez-Rodríguez D, et al. Brain-derived neurotrophic factor alleviates the oxidative stress induced by oxygen and glucose deprivation in an ex vivo brain slice model. Journal of cellular physiology. 2019;234(6):9592-9604.

11. Picón-Pagès $P$, Garcia-Buendia J, Muñoz FJ. Functions and dysfunctions of nitric oxide in brain. Biochimica et Biophysica Acta (BBA)-Molecular Basis of Disease. 2019;1865(8):1949-1967.

12. Tfelt-Hansen P. Pharmacological strategies to treat attacks of episodic migraine in adults. Expert Opinion on Pharmacotherapy. 2021;22(3):305-316.

13. Calabresi P, Cupini L. Medication-overuse headache: pathophysiological insights. The journal of headache and pain. 2005;6(4):199-202.

14. Tepper SJ. Medication-overuse headache. Continuum (Minneap Minn). Aug 2012;18(4):807-22. doi:10.1212/01.CON.0000418644.32032.7b

15. Xu H, Richardson JS, Li X-M. Doserelated effects of chronic antidepressants on neuroprotective proteins BDNF, Bcl-2 and Cu/Zn-SOD in rat hippocampus. Neuropsychopharmacology. 2003;28(1):53.

16. Burgos-Vega CC, Quigley LD, Avona A, Price T, Dussor G. Dural stimulation in rats causes BDNFdependent priming to subthreshold stimuli including a migraine trigger. Pain. 2016;157(12):2722.

17. Fidan I, Yüksel S, Ýmir T, İrkeç C, Aksakal FN. The importance of cytokines, chemokines and nitric oxide in pathophysiology of migraine. Journal of Neuroimmunology. 2006/02/01/ 2006;171(1):184-188. 
doi:https://doi.org/10.1016/j.jneuroim.2005.10.005

18. STARLING AJ. SEEDS for success: Lifestyle management in migraine. Cleveland Clinic journal of medicine. 2019;86(11):741.

19. Lemmens J, De Pauw J, Van Soom T, et al. The effect of aerobic exercise on the number of migraine days, duration and pain intensity in migraine: a systematic literature review and meta-analysis. J Headache Pain. Feb 2019;20(1):16. doi:10.1186/s10194-019-0961-8

20. Naugle KM, Fillingim RB, Riley III JL. A meta-analytic review of the hypoalgesic effects of exercise. The Journal of pain. 2012;13(12):1139-1150.

21. Lima LV, Abner TS, Sluka KA. Does exercise increase or decrease pain? Central mechanisms underlying these two phenomena. The Journal of physiology. 2017;595(13):4141-4150.

22. Andreou AP, Goadsby PJ. Therapeutic potential of novel glutamate receptor antagonists in migraine. Expert opinion on investigational drugs. 2009;18(6):789-803.

23. Wang DD, Kriegstein AR. GABA regulates excitatory synapse formation in the neocortex via NMDA receptor activation. Journal of Neuroscience. 2008;28(21):5547-5558.

24. Manzoni O, Prezeau L, Marin P, et al. Nitric oxide-induced blockade of NMDA receptors. Neuron. Apr 1992;8(4):653-62. doi:10.1016/0896-6273(92)90087-t

25. Ye ZC, Sontheimer H. Cytokine modulation of glial glutamate uptake: a possible involvement of nitric oxide. Neuroreport. Sep 1996;7(13):2181-5. doi:10.1097/00001756-199609020-00025

26. Ramadan NM. The link between glutamate and migraine. CNS spectrums. 2003;8(6):446-449.

27. Cotman CW, Berchtold NC. Exercise: a behavioral intervention to enhance brain health and plasticity. Trends Neurosci. Jun 2002;25(6):295-301.

28. Xu B. BDNF (I)rising from Exercise. Cell Metabolism. 2013/11/05/ 2013;18(5):612-614. doi:https://doi.org/10.1016/j.cmet.2013.10.008

29. Almeida R, Manadas B, Melo C, et al. Neuroprotection by BDNF against glutamate-induced apoptotic cell death is mediated by ERK and PI3-kinase pathways. Cell death and differentiation. 2005;12(10):1329.

30. Martínez F, Castillo J, Rodríguez JR, Leira R, Noya M. Neuroexcitatory amino acid levels in plasma and cerebrospinal fluid during migraine attacks. Cephalalgia. 1993;13(2):89-93.

31. Marosi K, Mattson MP. BDNF mediates adaptive brain and body responses to energetic challenges. Trends Endocrinol Metab. Feb 2014;25(2):89-98. doi:10.1016/j.tem.2013.10.006 
32. Sparks DL. The brainstem control of saccadic eye movements. Nature Reviews Neuroscience. 2002;3(12):952-964.

33. Dorner GT, Garhofer G, Kiss B, et al. Nitric oxide regulates retinal vascular tone in humans. American Journal of Physiology-Heart and Circulatory Physiology. 2003;285(2):H631-H636.

34. Savchenko A, Barnes S, Kramer RH. Cyclic-nucleotide-gated channels mediate synaptic feedback by nitric oxide. Nature. 1997 Dec 18-25 1997;390(6661):694-8. doi:10.1038/37803

35. Matteo BM, Viganò B, Cerri CG, Perin C. Visual field restorative rehabilitation after brain injury. Journal of vision. 2016;16(9):11-11.

36. Ploughman M, Granter-Button S, Chernenko G, et al. Exercise intensity influences the temporal profile of growth factors involved in neuronal plasticity following focal ischemia. Brain Research. 2007/05/30/ 2007;1150:207-216. doi:https://doi.org/10.1016/j.brainres.2007.02.065

37. Dinç ME, Muluk NB, Vonakis BM. Physiology of the Nose and Paranasal Sinuses. All Around the Nose. Springer; 2020:57-63.

38. Oldfield RC. The assessment and analysis of handedness: the Edinburgh inventory. Neuropsychologia. 1971;9(1):97-113.

39. van den Brink AM, MacGregor EA. Gender and Migraine. Springer; 2019.

40. Labastida-Ramírez A, Rubio-Beltrán E, Villalon CM, MaassenVanDenBrink A. Gender aspects of CGRP in migraine. Cephalalgia. 2019;39(3):435-444.

41. Kurth T, Slomke M, Kase C, et al. Migraine, headache, and the risk of stroke in women: a prospective study. Neurology. 2005;64(6):1020-1026.

42. (IHS) HCCotlHS. The International Classification of Headache Disorders, 3rd edition (beta version). Cephalalgia. Jul 2013;33(9):629-808. doi:10.1177/0333102413485658

43. Ferrari A, Baraldi C, Sternieri E. Medication overuse and chronic migraine: a critical review according to clinical pharmacology. Expert Opin Drug Metab Toxicol. Jul 2015;11(7):1127-44. doi:10.1517/17425255.2015.1043265

44. Diener H-C, Tassorelli C, Dodick DW, et al. Guidelines of the International Headache Society for controlled trials of preventive treatment of migraine attacks in episodic migraine in adults. Cephalalgia. 2020;40(10):1026-1044.

45. Silberstein S, Tfelt-Hansen P, Dodick DW, et al. Guidelines for controlled trials of prophylactic treatment of chronic migraine in adults. Cephalalgia. 2008;28(5):484-495. 
46. Niere K, Jerak A. Measurement of headache frequency, intensity and duration: comparison of patient report by questionnaire and headache diary. Physiotherapy research international. 2004;9(4):149156.

47. Tassorelli C, Diener H-C, Dodick DW, et al. Guidelines of the International Headache Society for controlled trials of preventive treatment of chronic migraine in adults. Cephalalgia. 2018;38(5):815-832.

48. Lachin JM. Properties of simple randomization in clinical trials. Control Clin Trials. Dec 1988;9(4):312-26. doi:10.1016/0197-2456(88)90046-3

49. Jain S. Applied Physiology of Eye Movements. In: Jain S, ed. Simplifying Strabismus : A Practical Approach to Diagnosis and Management. Springer International Publishing; 2019:15-22.

50. Leigh RJ, Zee DS. The neurology of eye movements. OUP USA; 2015.

51. Lampl C, Rudolph M, Deligianni Cl, Mitsikostas DD. Neck pain in episodic migraine: premonitory symptom or part of the attack? The journal of headache and pain. 2015;16(1):80.

52. Guyenet Patrice G, Bayliss Douglas A. Neural Control of Breathing and CO2 Homeostasis. Neuron. 2015/09/02/ 2015;87(5):946-961. doi:https://doi.org/10.1016/j.neuron.2015.08.001

53. Adler D, Herbelin B, Similowski T, Blanke O. Reprint of "Breathing and sense of self: Visuorespiratory conflicts alter body self-consciousness". Respiratory Physiology \& Neurobiology. 2014/12/01/ 2014;204:131-137. doi:https://doi.org/10.1016/j.resp.2014.09.019

54. Jo S-H. How to Sit in Sitting Meditation. Mindfulness. 2019;10(11):2468-2471.

55. van der Horst N, Smits D-W, Petersen J, Goedhart EA, Backx FJ. The preventive effect of the nordic hamstring exercise on hamstring injuries in amateur soccer players: a randomized controlled trial. The American journal of sports medicine. 2015;43(6):1316-1323.

56. Panda S. The Circadian Code: Lose Weight, Supercharge Your Energy, and Transform Your Health from Morning to Midnight. Rodale Books; 2020.

57. Bertisch S, Li W, Buettner C, et al. 1017 Sleep Duration, Fragmentation, And Quality And Risk Of Next-day Migraine. Sleep. 2018;41:A377.

58. Finan PH, Goodin BR, Smith MT. The association of sleep and pain: an update and a path forward. J Pain. Dec 2013;14(12):1539-52. doi:10.1016/j.jpain.2013.08.007

59. Barraj L, Scrafford C, Lantz J, Daniels C, Mihlan G. Within-day drinking water consumption patterns: results from a drinking water consumption survey. J Expo Sci Environ Epidemiol. May 2009;19(4):382-95. doi:10.1038/jes.2008.28 
60. Ketchesin KD, Becker-Krail D, McClung CA. Mood-related central and peripheral clocks. European Journal of Neuroscience. 2020;51(1):326-345.

61. Karapanou V, Kempuraj D, Theoharides T. Oral neuroimmune network and mast cells. SAGE Publications Sage UK: London, England; 2009.

62. Fornari RV, Aerni A, Dominique J-F, Roozendaal B. Neurobiological Mechanisms of Stress and Glucocorticoid Effects on Learning and Memory: Implications for Stress Disorders on Earth and in Space. Stress Challenges and Immunity in Space. Springer; 2020:95-122.

63. Kempuraj D, Mentor S, Thangavel R, et al. Mast Cells in Stress, Pain, Blood-Brain Barrier, Neuroinflammation and Alzheimer's. Mast Cells in Itch, Pain and Neuro-inflammation. 2020;

64. La Touche R, Fernández Pérez JJ, Proy Acosta A, et al. Is aerobic exercise helpful in patients with migraine? A systematic review and meta-analysis. Scandinavian Journal of Medicine \& Science in Sports. 2020;

65. Goadsby PJ, Lipton RB, Ferrari MD. Migraine-current understanding and treatment. New England journal of medicine. 2002;346(4):257-270.

66. Rainero I, Roveta F, Vacca A, Noviello C, Rubino E. Migraine pathways and the identification of novel therapeutic targets. Expert Opinion on Therapeutic Targets. 2020:1-9.

67. Benatto MT, Bevilaqua-Grossi D, Carvalho GF, et al. Kinesiophobia is associated with migraine. Pain Medicine. 2019;20(4):846-851.

68. Scholten-Peeters GG, Coppieters MW, Durge TS, Castien RF. Fluctuations in local and widespread mechanical sensitivity throughout the migraine cycle: a prospective longitudinal study. The Journal of Headache and Pain. 2020;21(1):1-11.

69. Holmberg JM. Pathophysiology, Differential Diagnosis, and Management of Persistent PosturalPerceptual Dizziness: A Review. Perspectives of the ASHA Special Interest Groups. 2020:1-11.

70. Schurger A, Sitt JD, Dehaene S. An accumulator model for spontaneous neural activity prior to self-initiated movement. Proceedings of the National Academy of Sciences. 2012;109(42):E2904-E2913.

71. Murakami M, Vicente Ml, Costa GM, Mainen ZF. Neural antecedents of self-initiated actions in secondary motor cortex. Nature neuroscience. 2014;17(11):1574.

72. Schurger A, Mylopoulos M, Rosenthal D. Neural antecedents of spontaneous voluntary movement: a new perspective. Trends in Cognitive Sciences. 2016;20(2):77-79.

73. Csermely P, Kunsic N, Mendik P, et al. Learning of signaling networks: molecular mechanisms. Trends in Biochemical Sciences. 2020; 
74. Bolam J, Hanley J, Booth P, Bevan M. Synaptic organisation of the basal ganglia. The Journal of Anatomy. 2000;196(4):527-542.

75. Santamaria L, Noreika V, Georgieva S, Clackson K, Wass S, Leong V. Emotional valence modulates the topology of the parent-infant inter-brain network. Neurolmage. 2020;207:116341.

76. Burke MJ, Joutsa J, Cohen AL, et al. Mapping migraine to a common brain network. Brain. 2020;

77. Srivastava A, Ahmad OF, Pacia CP, Hallett M, Lungu C. The Relationship between Saccades and Locomotion. Journal of movement disorders. 2018;11(3):93.

78. Rucker J. Eye Movement Abnormalities in Movement Disorders. Encyclopedia of Movement Disorders. 2010;1:462.

79. Coiner B, Pan H, Bennett ML, et al. Functional neuroanatomy of the human eye movement network: a review and atlas. Brain Structure and Function. 2019;224(8):2603-2617.

80. Caulo M, Maruotti V, Ferretti A. Brain Imaging of Pain. Pain Imaging. Springer; 2019:7-22.

81. Shepard NT, Schubert MC, Eggers SD. Eye Movement Recording and Ocular Motility Testing. Balance Function Assessment and Management. 2020:189.

82. Klein C, Ettinger U. Eye Movement Research: An Introduction to Its Scientific Foundations and Applications. Springer Nature; 2019.

83. Perrin P, Schneider D, Deviterne D, Perrot C, Constantinescu L. Training improves the adaptation to changing visual conditions in maintaining human posture control in a test of sinusoidal oscillation of the support. Neuroscience letters. 1998;245(3):155-158.

84. Slagter HA, Vissers ME, Talsma LJ, Ridderinkhof KR. Cognitive enhancement: it's about time. Cognitive neuroscience. 2017;8(2):119-120.

85. Hutton SB. Cognitive control of saccadic eye movements. Brain and cognition. 2008;68(3):327340.

86. Pierrot-Deseilligny C, Milea D, Müri RM. Eye movement control by the cerebral cortex. Current opinion in neurology. 2004;17(1):17-25.

87. Liu J, Zhao L, Lei F, et al. Disrupted resting-state functional connectivity and its changing trend in migraine suffers. Human brain mapping. 2015;36(5):1892-1907.

88. Park H-D, Barnoud C, Trang H, Kannape OA, Schaller K, Blanke O. Breathing is coupled with voluntary action and the cortical readiness potential. Nature Communications. 2020;11(1):1-8. 
89. Martarelli D, Cocchioni M, Scuri S, Pompei P. Diaphragmatic breathing reduces exercise-induced oxidative stress. Evidence-Based Complementary and Alternative Medicine. 2011;2011

90. Sclocco R, Garcia RG, Kettner NW, et al. The influence of respiration on brainstem and cardiovagal response to auricular vagus nerve stimulation: a multimodal ultrahigh-field (7T) fMRI study. Brain stimulation. 2019;12(4):911-921.

91. Vila-Pueyo M, Hoffmann J, Romero-Reyes M, Akerman S. Brain structure and function related to headache: Brainstem structure and function in headache. Cephalalgia. Jan 2018:333102418784698. doi:10.1177/0333102418784698

92. Reiter RJ, Tan DX, Maldonado MD. Melatonin as an antioxidant: physiology versus pharmacology. Journal of pineal research. 2005;39(2):215-216.

93. Peña LO, Martínez MS, Carmona AF. Spontaneous Breathing Pattern. Ventilatory Support and Oxygen Therapy in Elder, Palliative and End-of-Life Care Patients. Springer; 2020:3-13.

\section{Tables}

Table 1.

Mean and $S D s$ for demographic information, history of migraine, and distribution of participants based on socioeconomic status and type of migraine in study groups.

\begin{tabular}{|c|c|c|c|c|c|c|c|}
\hline \multicolumn{8}{|c|}{ Groups } \\
\hline \multicolumn{2}{|c|}{ Variables } & $\begin{array}{c}\text { Eye } \\
\text { movement }\end{array}$ & $\begin{array}{c}\text { Diaphragmatic } \\
\text { Breathing }\end{array}$ & Control & $\begin{array}{c}F \\
(2,60)\end{array}$ & $\chi^{2}$ & $p$ \\
\hline \multirow[t]{4}{*}{$\begin{array}{c}\text { Mean } \\
(S D)\end{array}$} & Age & $\begin{array}{l}31.15 \\
(6.40)\end{array}$ & $31.61(4.87)$ & $\begin{array}{l}30.73 \\
(5.88)\end{array}$ & .09 & & .90 \\
\hline & $\begin{array}{l}\text { Weight } \\
\text { (Kg) }\end{array}$ & $\begin{array}{l}61.95 \\
(7.51)\end{array}$ & $61.39(7.77)$ & $\begin{array}{l}62.07 \\
(8.08)\end{array}$ & .03 & & .96 \\
\hline & $\begin{array}{l}\text { Height } \\
\text { (cm) }\end{array}$ & $\begin{array}{l}163.75 \\
(6.98)\end{array}$ & $162.50(5.53)$ & $\begin{array}{c}162.93 \\
(6.79)\end{array}$ & .18 & & .83 \\
\hline & HM (yr.) & $5.00(3.06)$ & $4.39(2.63)$ & $4.93(3.36)$ & .22 & & .80 \\
\hline \multirow[t]{2}{*}{$\mathrm{N}$} & SES* & $4: 14: 2$ & $3: 13: 2$ & & $5: 8: 2$ & 1.70 & .79 \\
\hline & MT & $8: 12$ & $3: 15$ & & $6: 9$ & 2.97 & .22 \\
\hline
\end{tabular}

$\overline{\text { Note. HM }}=$ History of Migraine, SES = Socioeconomic Status (*high: middle: Low), and MT = Migraine Type (MwA = Migraine with aura or MwoA = Migraine without aura) in study groups. The groups did not significantly differ in demographic characteristics, SES, and MT. 
Table 2.

Mean and SDs for frequency, duration, and intensity of migraine pain in each study group across three assessment points.

\begin{tabular}{|c|c|c|c|c|c|c|c|c|c|}
\hline \multirow{2}{*}{$\begin{array}{l}\text { Groups; Mean } \\
(S D)\end{array}$} & \multicolumn{3}{|c|}{ Frequency } & \multicolumn{3}{|c|}{ Duration } & \multicolumn{3}{|c|}{ Intensity } \\
\hline & Pre-test & $\begin{array}{c}\text { Post- } \\
\text { test }\end{array}$ & $\begin{array}{c}\text { Follow- } \\
\text { up }\end{array}$ & Pre-test & Post-test & $\begin{array}{c}\text { Follow- } \\
\text { up }\end{array}$ & Pre-test & Post-test & $\begin{array}{c}\text { Follow- } \\
\text { up }\end{array}$ \\
\hline$\overline{\mathrm{EME}}$ & $\begin{array}{c}9.15 \\
(2.68)\end{array}$ & $\begin{array}{c}2.40 \\
(1.46)\end{array}$ & $\begin{array}{c}2.70 \\
(1.21)\end{array}$ & $\begin{array}{c}8.10 \\
(3.29)\end{array}$ & $\begin{array}{c}1.80 \\
(1.36)\end{array}$ & $\begin{array}{c}1.95 \\
(0.99)\end{array}$ & $\begin{array}{c}6.50 \\
(1.67)\end{array}$ & $\begin{array}{l}1.20 \\
(0.83)\end{array}$ & $\begin{array}{c}2.20 \\
(0.95)\end{array}$ \\
\hline DB & $\begin{array}{c}8.22 \\
(4.00)\end{array}$ & $\begin{array}{c}1.61 \\
(1.24)\end{array}$ & $\begin{array}{c}1.44 \\
(1.79)\end{array}$ & $\begin{array}{c}6.50 \\
(2.77)\end{array}$ & $\begin{array}{c}0.89 \\
(0.67)\end{array}$ & $\begin{array}{c}1.11 \\
(1.41)\end{array}$ & $\begin{array}{c}6.11 \\
(1.32)\end{array}$ & $\begin{array}{c}0.94 \\
(0.72)\end{array}$ & $\begin{array}{c}1.50 \\
(1.29)\end{array}$ \\
\hline Control & $\begin{array}{c}8.80 \\
(2.48)\end{array}$ & $\begin{array}{c}8.33 \\
(2.66)\end{array}$ & $\begin{array}{c}9.20 \\
(4.34)\end{array}$ & $\begin{array}{c}8.07 \\
(3.97)\end{array}$ & $\begin{array}{c}8.00 \\
(3.87)\end{array}$ & $\begin{array}{c}7.80 \\
(3.07)\end{array}$ & $\begin{array}{c}7.07 \\
(1.79)\end{array}$ & $\begin{array}{c}6.80 \\
(1.56)\end{array}$ & $\begin{array}{c}6.20 \\
(1.29)\end{array}$ \\
\hline
\end{tabular}

Note. EME = Eye movement exercises; $\overline{\mathrm{DB}}=$ = Diaphragmatic Breathing; Frequency = headache days for four weeks-over three months; Duration $=4-72$ hours per attack; Intensity $=1-10$ from a visual analog scale (VAS).

Table 3.

Results of three MANCOVA models testing inter-group effects at post-test and a 12-month follow-up.

\begin{tabular}{|c|c|c|c|c|c|c|c|}
\hline \multirow[b]{2}{*}{ DVs } & & \multirow[b]{2}{*}{ Assessment } & \multicolumn{4}{|c|}{ Main effects } & \multirow{2}{*}{$\begin{array}{c}\text { Pairwise } \\
\text { comparisons } \\
(p<001)\end{array}$} \\
\hline & & & $\begin{array}{c}\text { Wilks' } \lambda \\
(4,96)\end{array}$ & $\begin{array}{c}F(4, \\
96)\end{array}$ & $p$ & $\begin{array}{c}\eta^{2} \\
\text { (Cohen's } \\
\text { d) }\end{array}$ & \\
\hline \multirow[t]{6}{*}{$\begin{array}{c}\text { Migraine } \\
\text { attacks }\end{array}$} & \multirow[t]{2}{*}{ Frequency } & Post-test & \multirow[t]{2}{*}{0.20} & 78.59 & .001 & $\begin{array}{c}.79 \\
(3.55)\end{array}$ & $\begin{array}{c}\mathrm{ME \& DB}< \\
\text { Ctrl }\end{array}$ \\
\hline & & Follow-up & & 50.93 & .001 & $\begin{array}{c}.67 \\
(2.84)\end{array}$ & $\begin{array}{c}\mathrm{ME} \& \mathrm{DB}< \\
\mathrm{Ctrl}\end{array}$ \\
\hline & \multirow[t]{2}{*}{ Duration } & Post-test & \multirow[t]{2}{*}{0.16} & 89.28 & .001 & $\begin{array}{c}.78 \\
(3.76)\end{array}$ & $\begin{array}{c}\text { ME\&DB }< \\
\text { Ctrl }\end{array}$ \\
\hline & & Follow-up & & 77.40 & .001 & $\begin{array}{c}.76 \\
(3.55)\end{array}$ & $\begin{array}{c}\text { ME\&DB }< \\
\text { Ctrl }\end{array}$ \\
\hline & \multirow[t]{2}{*}{ Intensity } & Post-test & \multirow[t]{2}{*}{0.09} & 166.81 & .001 & $\begin{array}{c}.87 \\
(5.17)\end{array}$ & $\begin{array}{c}\mathrm{ME} \& \mathrm{DB}< \\
\mathrm{Ctrl}\end{array}$ \\
\hline & & Follow-up & & 69.53 & .001 & $\begin{array}{c}.73 \\
(3.28)\end{array}$ & $\begin{array}{c}\text { ME\&DB }< \\
\text { Ctrl }\end{array}$ \\
\hline
\end{tabular}


Table 4.

Results of Cochran's $Q$ models testing inter-group effects at post-test and a 12-month followup.

\begin{tabular}{|c|c|c|c|c|c|c|c|}
\hline \multirow[b]{2}{*}{ Variables } & \multirow[b]{2}{*}{ Factors } & \multirow[b]{2}{*}{ Groups } & \multicolumn{3}{|c|}{ Frequency } & \multirow[b]{2}{*}{$\begin{array}{c}\text { Cochran's } \\
Q\end{array}$} & \multirow[b]{2}{*}{$P$} \\
\hline & & & $\begin{array}{l}\text { Pre- } \\
\text { test }\end{array}$ & $\begin{array}{c}\text { Post- } \\
\text { test }\end{array}$ & $\begin{array}{l}\text { Follow- } \\
\text { up }\end{array}$ & & \\
\hline \multirow[t]{3}{*}{ Menstrual Cycle } & \multirow[t]{3}{*}{ No Effect : Increase } & $\overline{\mathrm{EME}}$ & $13: 5$ & $18: 0$ & $18: 0$ & 10.00 & $\overline{.007}$ \\
\hline & & $\overline{\mathrm{DB}}$ & $15: 5$ & $20: 0$ & $20: 0$ & 10.00 & .007 \\
\hline & & $\overline{\text { Control }}$ & $10: 5$ & $11: 4$ & $14: 1$ & 6.50 & .03 \\
\hline \multirow{3}{*}{$\begin{array}{l}\text { Over the } \\
\text { Counter }\end{array}$} & \multirow[t]{3}{*}{ No Use : Use } & $\overline{\mathrm{EME}}$ & $0: 18$ & $2: 16$ & $4: 14$ & 4.80 & .09 \\
\hline & & $\overline{\mathrm{DB}}$ & $0: 20$ & $7: 13$ & $4: 16$ & 9.25 & .01 \\
\hline & & $\overline{\text { Control }}$ & $2: 13$ & $1: 14$ & $1: 14$ & .66 & .71 \\
\hline \multirow[t]{3}{*}{ Wake_up_Mode } & \multirow{3}{*}{$\begin{array}{l}\text { Refreshed : Sleepy or } \\
\text { Tired }\end{array}$} & $\overline{\mathrm{EME}}$ & $5: 13$ & $18: 0$ & $18: 0$ & 26.00 & .001 \\
\hline & & $\overline{\mathrm{DB}}$ & $0: 20$ & $19: 1$ & $18: 2$ & 34.30 & .001 \\
\hline & & $\overline{\text { Control }}$ & $3: 12$ & $1: 14$ & $0: 15$ & 4.66 & .09 \\
\hline \multirow[t]{3}{*}{ Sleep Hours } & Less than Seven Hours : & $\overline{\mathrm{EME}}$ & $16: 2$ & $9: 9$ & $12: 6$ & 5.69 & .05 \\
\hline & \multirow[t]{2}{*}{ More than Seven Hours } & $\overline{\mathrm{DB}}$ & $18: 2$ & $14: 6$ & $12: 8$ & 4.30 & .11 \\
\hline & & $\overline{\text { Control }}$ & $13: 2$ & $13: 2$ & $13: 2$ & 0.00 & 1.00 \\
\hline \multirow{3}{*}{$\begin{array}{l}\text { Sleeping } \\
\text { Pattern }\end{array}$} & \multirow[t]{3}{*}{$\overline{\text { On time : Late }}$} & $\overline{\mathrm{EME}}$ & $4: 14$ & $12: 6$ & $15: 3$ & 14.92 & .001 \\
\hline & & $\overline{\mathrm{DB}}$ & $3: 17$ & $14: 6$ & $13: 7$ & 13.87 & .001 \\
\hline & & $\overline{\text { Control }}$ & $2: 13$ & $1: 14$ & $1: 14$ & 0.66 & .71 \\
\hline \multirow[t]{3}{*}{ Drinking water } & \multirow[t]{3}{*}{$\overline{\text { No }: \text { Yes }}$} & $\overline{\mathrm{EME}}$ & $14: 4$ & $1: 17$ & $0: 18$ & 24.40 & .001 \\
\hline & & $\overline{\mathrm{DB}}$ & $19: 1$ & $3: 17$ & $6: 14$ & 24.11 & .001 \\
\hline & & $\overline{\text { Control }}$ & $14: 1$ & $13: 2$ & $13: 2$ & .66 & .717 \\
\hline
\end{tabular}

Note. EME $=$ Eye movement exercises; $\overline{D B}=\overline{\text { Diaphragmatic }} \overline{\text { breathing }}$

Figures 


\section{Enrollment}

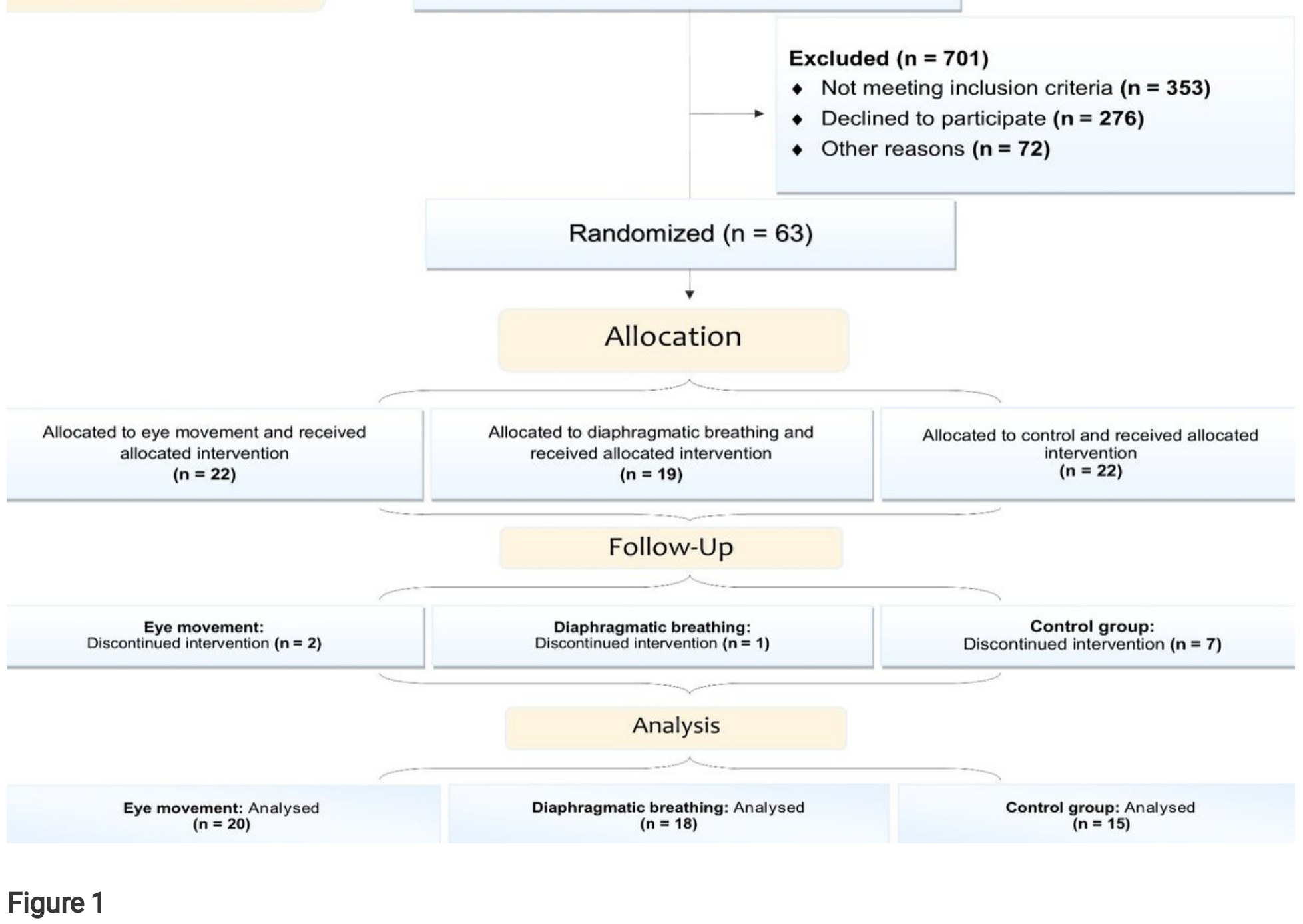

Flow of study population from 2016 to 2019 . 

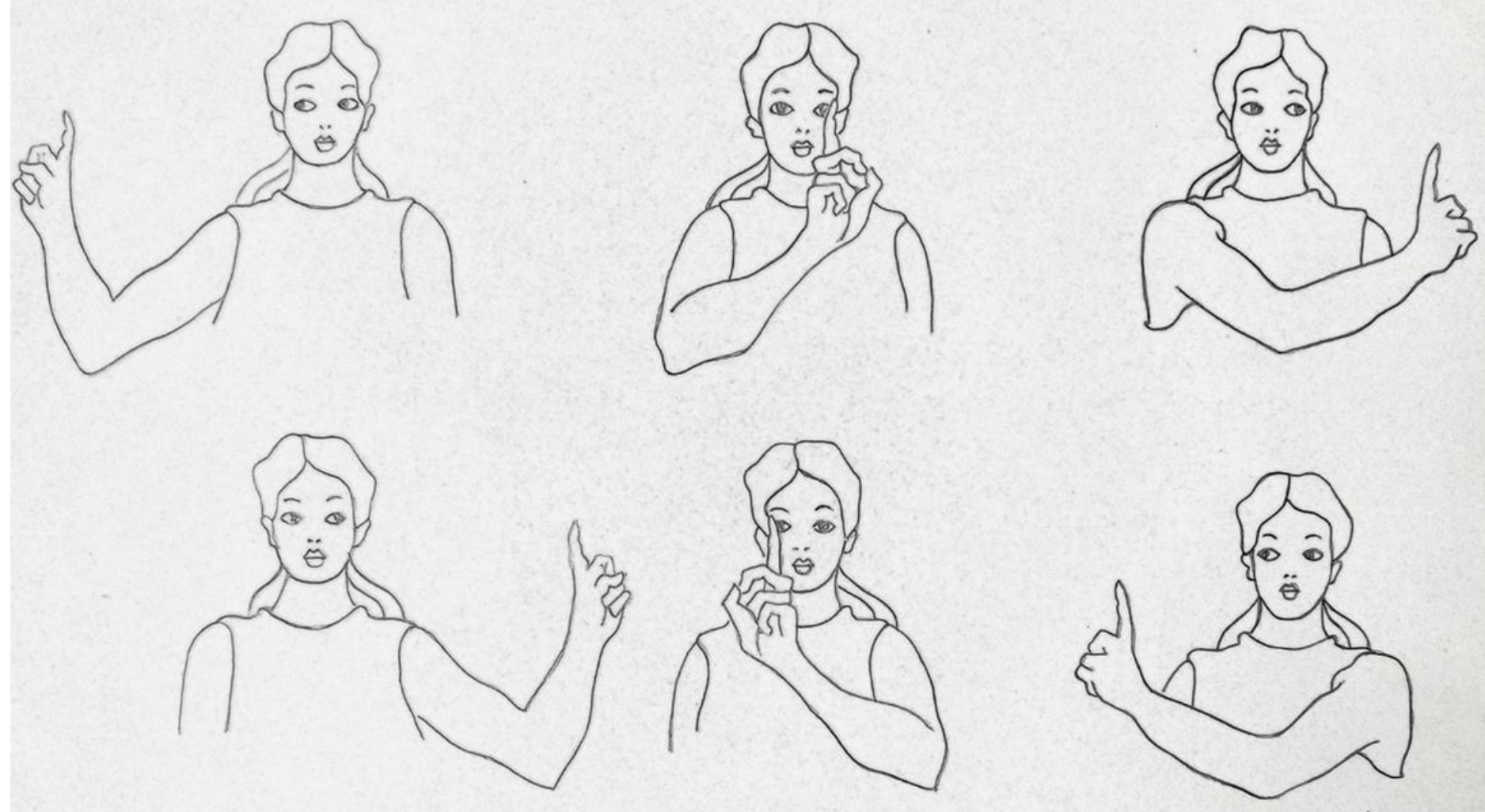

\section{Figure 2}

Shows participants eye movement exercises for experimental groups: first row shows vertical headguided eye movement exercises; second row shows horizontal head-guided eye movement exercises.
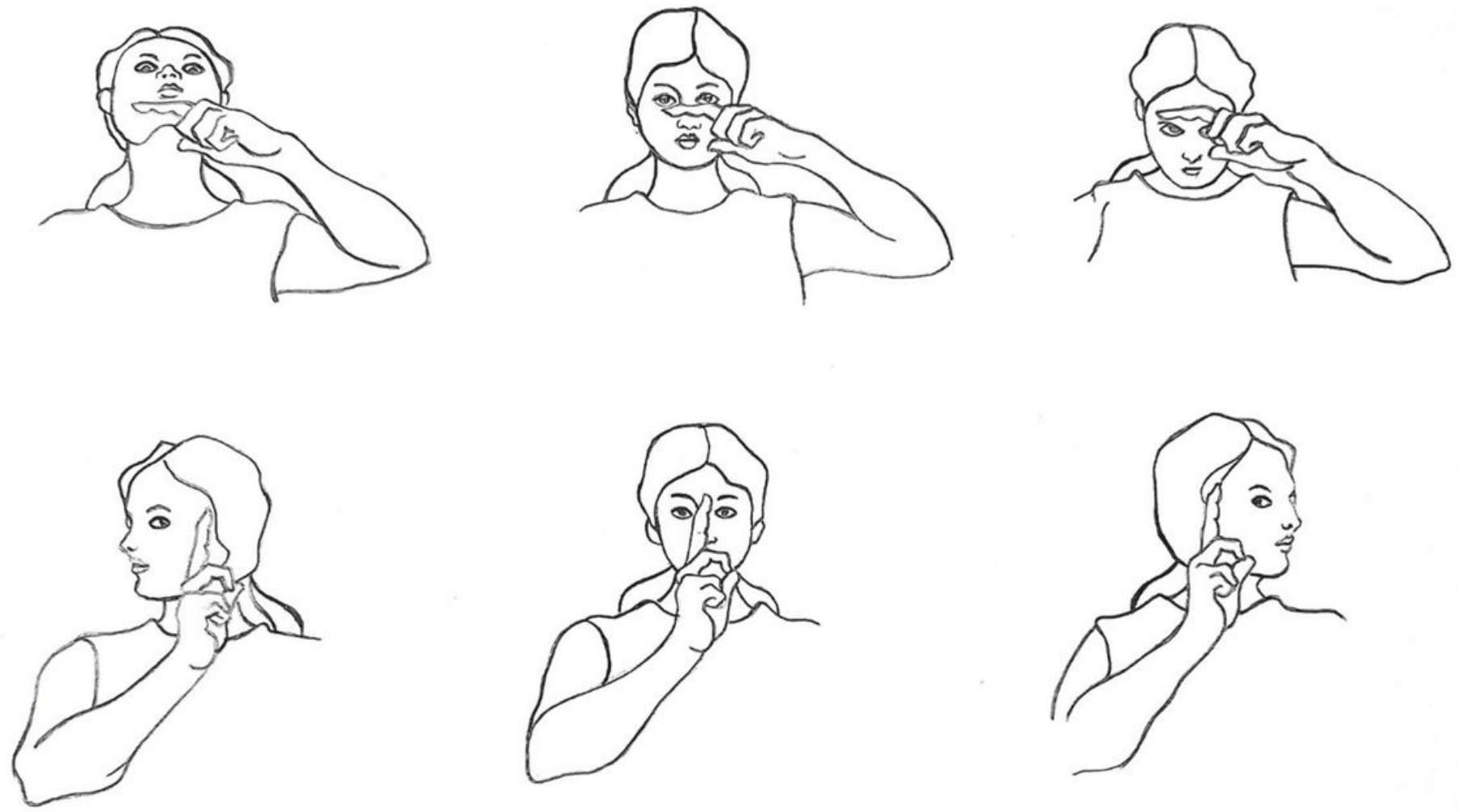


\section{Figure 3}

Shows participants eye movement exercises for experimental groups: first row shows vertical headguided eye movement exercises; second row shows horizontal head-guided eye movement exercises.

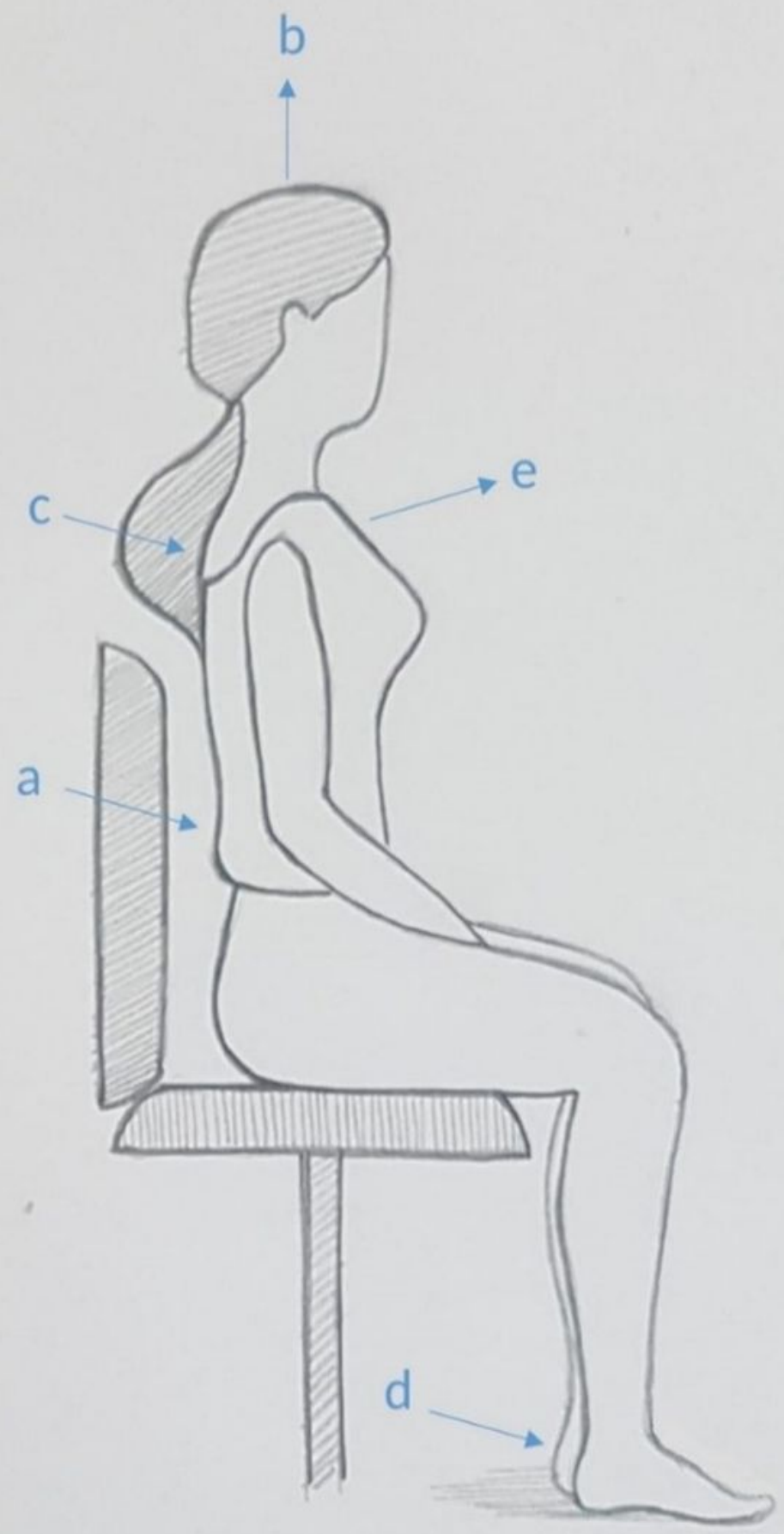

Figure 4 
Participants posture during eye movement exercises or diaphragmatic breathing: $a=$ upright back; $b=$ fixed, leveled, and high-up head; $c$ = rolled backed shoulders; $d$ = planted feet on the ground at a 90-degree angle to the extension of shoulders; $\mathrm{e}=$ slouched forward breast.

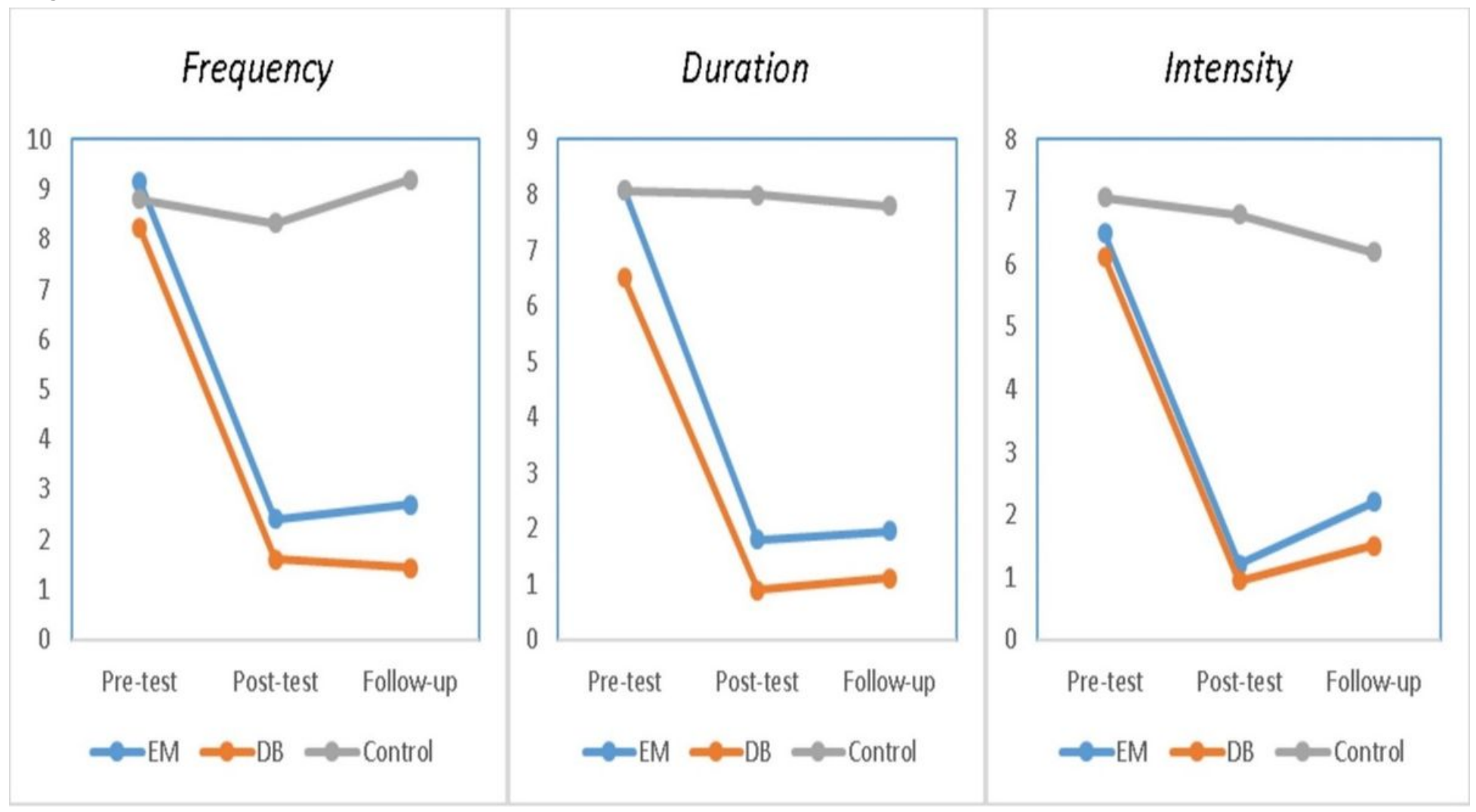

\section{Figure 5}

Migraine pain (frequency; ranges 1-9 attacks, duration; ranges 1-8 hours/attack, and intensity; ranges a scale of 1-7/attack during the last four-week) changes in each study (EM = eye movement exercises, $D B=$ diaphragmatic breathing, control) group across three assessment points (pre-test, pot-test, and followup). 